\title{
Implantable RFID Chips
}

\author{
Security versus Ethics
}

\author{
Vikas Kumar \\ Asia-Pacific Institute of Management, \\ 3 \&4 Institutional Area, Jasola, Sarita Vihar, \\ New Delhi - 110025, India \\ vk_aggarwalerediffmail.com
}

\begin{abstract}
Implantable RFID chips are being seen as a potential security device for the very near future with the availability of these chips already in the marketplace. The applications are presented in a broadly positive light in their use in contexts that range from health monitoring to emergency solutions. But there is a darker side to RFID chips: with their implantation, there may be an erosion of privacy and a breach in bodily integrity. In this paper, a variety applications of implantable RFID chips are discussed by taking a look at the particular technologies concerned. The legal and ethical aspects vis-à-vis the high-end security offered by such implants are compared with concerns about maintaining a democratic and sensitive society. Broadly, the paper contrasts the usefulness of RFID in industrial and other processes, with the ethical and health issues that are involved in human-implantable RFID.
\end{abstract}

\section{Introduction}

Commercially, there are some exciting and interesting new technological developments on the market today. Radio Frequency Identification (RFID) is a new automatic identification method using wireless technology. With the growing need of automatic identification procedures, there has been a tremendous revolution in the applications of RFID technology with RFID tags replacing bar-code tags in the fastgrowing retail industry [1]. The technology has really helped in the total management of the supply chain as well as in product outlets by using less human support and as a result of their high speed. With a predicted \$US10-billion market over the next decade, RFID is a booming new wireless technology with an eager new market retailers. The technology is transforming the way retailers receive, distribute, execute and merchandise goods to customers. Retailers today are embracing RFID as an enabling technology that will provide them with value beyond the supply chain. The commercial focus is now on transportation and logistics, healthcare and medical devices, pharmaceuticals, manufacturing, aviation and automotive sectors and the food supply chain. Successful RFID implementations have already been achieved in cars for moving through the toll gates, RFID-enabled credit cards (e.g. MasterCard's Paypass or Shell Oil's easypay) to speed up purchases or RFID-enabled transit passes

Please use the following format when citing this chapter:

Kumar, V., 2008, in IFIP International Federation for Information Processing, Volume 262; The Future of Identity in the Information Society; Simone Fischer-Hübner, Penny Duquenoy, Albin Zuccato, Leonardo Martucci; (Boston: Springer), pp. 151-157. 
like London's Oyster card. RFID is used in all areas of automatic data capture that allow contactless identification of objects using radio frequency. From the global giant Wal-Mart down to other smaller companies, RFID is being adapted to track inventories via microchip-tagged products.

With applications that range from secure internet payment systems to industrial automation and access control, RFID technology solutions are receiving much attention in the research and development departments of large corporations. As a result, the technology is being seen as a major application in automotive identification and production automation, allowing emergency vehicles to trip traffic signals safely and providing the technology behind examples such as contactless smart cards that "auto pilot" cars. RFID certainly appears to be proving itself a technology booster for the smart electronic society.

In the present work, characteristics of the RFID technology have been discussed first with a focus on human body implants. Applications of the technology have been listed in the present scenario and in particular with respect to the security. Along with this, an effort has been made to see the harmful health effects of the technology as a result of high frequency use. Finally a closer look has been taken to the ethical challenges raised by the technology concerning human society.

\section{Implantable RFID Chips}

Apart from their commercial use, direct applications of RFID technology to the human body are now seen as a potential future application; implantable RFID chips are now available in the marketplace [2][3]. Implantable RFID chips are already present in society with their practical use in hospitals and well as industry. An implantable RFID chip, which is durable and about the size of a grain of rice, can hold or link to information about the identity, physiological characteristics, health, nationality, and security clearances of the person concerned. We can imagine situations where your hand could start your car or unlock your front door or, if you were unconscious and in an emergency situation, could let a physician know about the vital characteristics.

RFID technology [4][5] works on the principle of radio frequency transmissionreception. An RFID system is made up of two components:

- A transponder, which is located on the object to be identified;

- A detector or reader, which, depending upon the design and the technology used, may be a read-only or a write/read device.

A transponder, which represents the actual data carrying device of an RFID system, normally consists of a coupling element and an electronic microchip. When the transponder, which does not usually possess its own voltage supply (or battery), is not within the response range of a reader, it is totally passive. The transponder is only activated when it is within the response range of a reader. The power required to activate the transponder is supplied to the transponder through the contactless coupling unit as is the timing pulse and data. 
A reader typically contains a high frequency module (transmitter and receiver), a control unit and a coupling element to the transponder. In addition, many readers are fitted with an additional interface to enable them to forward the data received to another system (like a personal computer).

\section{Applications of Implantable RFID Chips}

RFID technology applications are moving fast ahead towards human society. Humancentric applications of RFID [6] began in 1997 when a US patent for a "Personal Tracking and Recovery System" was registered [7]. The number of applications is increasing day by day, and has been reported widely in the literature [8-15].

At present, implantable chips are seen as a potential application for a form of permanent identity card that implies no need to carry personal documents. Once implanted, they could serve as the anytime, anywhere identity of the person concerned, and could serve as a single replacement of a number of identity cards. The chips have all been used for commercial, military as well as research applications. Implantable RFID chips have been designed and implanted successfully for animal tagging, and are now being used in some human beings, mainly experimentally. An early experiment with RFID implants was conducted by a British professor of cybernetics Kevin Warwick [16-17], who implanted a chip in his arm in 1998. Nowadays a number of night clubs in Barcelona, Spain, and in the Netherlands are using implantable chips to identify their very important (VIP) customers, who in turn use them to pay for drinks. The VeriChip Corporation [18] is a major company that deals in implantable or attachable chips. It has customized the devices for at least seven applications like (a) secure patient identification helping at-risk patients to get the right treatment when they need it most, (b) infant protection, (c) wander prevention to keep wander-prone residents safe, (d) an Assetrac system for locating different assets, (e) a tool and equipment management system that allows construction, maintenance and repair organizations to control their tools and equipment inventory, (f) vibration monitoring, and (g) emergency management solutions that allow users to manage, track, and inventory remains and evidentiary items accurately that are associated with small incidents, crime scenes, or mass disasters. The company claims a number of successful implementations of these implantable devices.

These implantable ICT devices represent the possible solution to a great need, with the rising demand for health services, increased mobility of the patients, and the need to limit occupational accidents and diseases [19]. For example, even though it did not explicitly or directly fund any RFID-related work, the European Commission in its fifth framework programme co-funded projects covering intelligent systems for health professionals, for patients and intelligent environments for the health of citizens [20] and, more recently, in its seventh framework programme, the Commission is funding a study that explores the use of RFID wireless technologies in hospitals in Europe. 
When looking at these overall scenarios, the potential applications could seem to be really wonderful and to provide a huge step towards the world of automation. However there are a number of problems associated with them that we will be discussing in the upcoming sections.

\section{Security Applications}

The most important applications of implantable chips still lie in the field of security management. These chips can have a potential role in the development of anti-terrorist security tools with automatic identification. For example, they are the most suitable means for keeping a watch on criminals in custody. As an illustration, most of the big criminals tend to free themselves from custody or prison; this has been seen a number of times in India as well as other countries [21]. Implantable RFID chips may offer great success in keeping sound security watch over such criminals. Also, RFID chips may be of good use for finding any security breach in the personal security of veryvery important persons by reporting automatically their presence and activities. So, there are numerous of fruitful applications that can be explored in terms of RFID implantable chips technology and can be used for the welfare of society.

But the most commonly used technologies always pose a security threat as the result of the work of hackers as they follow the advancing technology trends. This type of security hazard, when applied to RFID chips, can lead to drastic irreversible implications as the sensitivity of the relevant data or information tend to be very high particularly in relation to security applications. Thus the security applications of implantable chips must be used or applied with greater care.

However there are still a number of problems associated with the implantable chips, and the most significant of these are the health effects associated with radiation.

\section{Health Effects}

Normal RFID readers radiate electromagnetic field and magnetic fields in the close proximity of the tag. These fields activate circuitry on the tags and the data stored in the tag is retransmitted to the reader. The frequencies used are $13.56 \mathrm{MHz}$ and 915 $\mathrm{MHz}$ (UHF). A lot of research work has been carried out to see the effect of electromagnetic radiation on human body (even complete journals have been devoted to this field [22]), but no consistent results have been reported for radiation in the range of frequencies being used by RFID. Also a study has been undertaken to see the effect of radiation on the drug products that use RFID tags for retail marketing. The results [23] show that the energy supplied by these is not sufficient to give rise to a chemical change. Thus, presently, there is no suitable evidence of the possible health hazards. A lot of research work is still needed to explore the possible health hazards of this technology [24]. However considering human beings as social beings, social 
health is of even greater importance than personal health. Hence, social issues need to be considered in the implementation of this technology.

\section{Ethical Issues}

Ethics form the basis of effective human existence, and hence must be considered in the human centric applications of technology. The important, main concerns about the implementation of implantable RFID technology are the ethical and societal issues concerning the identity of human beings. As a specific example, with the growing need of identification, some educational institutes have installed biometric systems for the attendance of teachers in India, but the professors have taken a strong stance against this approach, since they see it as disregarding a highly respected profession [25].

In such a sensitive society, are we really ready to have identity chips implanted directly in our body? The situation may indicate that people are like 24-hour slaves rather than employees, and the universal law of 8 hours of work will not be valid. This will be an erosion of our privacy and our right to bodily integrity. Does anybody really want to be required to have a foreign object implanted in his/her arm just to either get or keep a job? And does the employee want the employer to know whenever s/he leaves the office? Also, should every RFID reader-equipped supermarket checkout counter note your presence and your purchases? Thus the personal life of people may always be at risk with continuous monitoring.

Implantable devices have serious ethical consequences as these devices are accessible via digital networks. This may lead to a situation where you are always insecure in your own secure home [26]. Subcutaneous RFID implants make peopletracking possible without the need for any correlation of profiling data or misuse of data. Consequently, this threat may cause a direct conflict with individual liberties. Such implants have the potential to form a basis for cyber-racism; they may be used to change the identity, memory, self perception and perception of others. The misuse of information certainly create ethically unacceptable instances as per the opinion of European Group on Ethics of Science and New Technologies, 2005. However this needs a further elaboration in particular with reference to the implantable RFID technology. In the worst case, they may be used to enhance capabilities in order to dominate others. Such applications, similar to human cloning, may tend to degrade the whole social system.

In the opinion of the European group on ethics [27], the implantation of ICT devices in the human body should be governed by the three principles that

(a) The objective is important, like saving lives, restoring health and improving the quality of life.

(b) The implant is necessary to achieve this objective.

(c) There is no method that is less invasive and more cost effective for achieving the same objective.

The European group on ethics makes a general point that non-medical applications of ICT-implants are a potential threat to human dignity and democratic society. 
Therefore, such applications should respect in all circumstances the principles of informed consent and proportionality. Such implants are a potential threat to human dignity when they are used for surveillance purposes, as they may be used by state authorities, individuals or groups to increase their power over others. Hence the surveillance applications of ICT implants may only be permitted if the legislator considers that there is an urgent and justified necessity in a democratic society.

Thus society really needs a brainstorming exercise so as to decide on the applications and usability of RFID technology while maintaining the dignity and integrity of individuals.

\section{Conclusion}

Privacy advocates raise the issue of public awareness and aid in ensuring that technology is deployed responsibly, but ultimately consumers will drive the use of technology through their behaviours, preferences and demands. This paper summarizes the key applications of implantable RFID chips, by taking a closer look at the ethical and legal aspects of such implants in relation to human society. It is concluded that implantable RFID chip technology certainly has the potential to address the security concerns of present-day information society. But at the same time, the social and ethical issues (including privacy and health issues) must be taken care of before implementation. Technology has always been a leader in taking human society ahead of imagination. A careful constructive approach to RFID, used with increased awareness and perception, will certainly help society with tremendous applications.

\section{Acknowledgement}

The author is thankful to the reviewers of the paper for their comments and suggestions. They have certainly helped a lot in improving the quality of paper.

\section{References}

1. "euroRFID - your guide to RFID \& GDS solutions", [Available at www.escinst.org]

2. Kenneth R.Foster and Jan Jaeger,"RFID Inside", IEEE Spectrum Magazine, March 2007

3. Amal Graafstra,"Hands On", IEEE Spectrum Magazine, March 2007

4. Sandip Lahiri, "RFID Source Book", IBM Press 2006

5. http://rfid-handbook.de/

6. Masters A and Michael K, "Humancentric applications of RFID implants: The Usability Contexts of Control, Convenience and Care", proceedings of $2^{\text {nd }}$ International workshop on Mobile commerce and Services, July 19, 2005, pp 32-41

7. Paul A Gargano et al., "Personal tracking and recovery system", United States Patent Number 5629678, 1997 
8. D. Icke, "Has The Old ID Card had Its Chips?" Soldier Magazine, April, 2001

9. C. Murray, "Injectable Chip Opens door to Human Bar Code", EE Times, January 7, 2002

10. J. Scheers, "New Body Art: Chip Implants", Wired News, March 11, 2002

11. J. Black, "Roll Up your Sleeves for a Chip Implant", Business Week Online, Business Week Magazine, March 21, 2002

12. L. Grossman, "Meet the Chipsons", Time, New York, 159(10), March 11, 2002 pp. 56-57

13. D. Stretfeld, "Chips To Be Implanted in Humans", Los Angeles Times, May 10, 2002

14. B. Gengler, "Chip Implants Become Part of You”, The Australian, September 10, 2002

15. R. Woolnaugh, "A man with a chip in his shoulder", Computer Weekly, June 29, 2000

16. http://www.kevinwarwick.com/

17. Mark Gasson, "ICT Implants", Presentation at IFIP Summer School, Karlstad, 2007

18. http://www.verichipcorp.com/

19. Diane Whitehouse, "Information communication technologies and health: past, current and future directions", Proceedings of IFIP Summer School pp. 211-218

20. European Communities 2000-IST Programme. Report of the IST advisory group concerning trust, dependability, security and privacy for IST in FP6

21. http://in.news.yahoo.com/071024/43/6md4a.html

22. Bioelectromagnetics, John Wiley \& Sons

23. H. Bassen, S. Seidman, J. Rogul at al.,"An Exposure System for Evaluating Possible Effects of RFID on Various Formulations of Drug Products", IEEE Applications and Practice Magazine, April 2007, pp. 17-23

24. European Commission Report, "User Needs in ICT Research for Independent Living, with a Focus on Health Aspects", European Communities, 2006

25. Asia-Pacific Institute of Management, New Delhi (2007)

26. Simon Garfinkel, "Database Nation: The Death of Privacy in the $20^{\text {th }}$ Century", O'Reilly \& Associates, Inc., 2000

27. European Commission Report, "Opinion on the ethical aspects of ICT implants in the human body (Opinion No. 20)”, European Communities, 2005 